\title{
Menstrual Pattern and Hygiene among Female Prisoners in Kano, North-western Nigeria
}

\author{
Rabiu A, Sani FM, ${ }^{2}$ Daneji SM. ${ }^{3}$ \\ ${ }_{1,3}^{1,3}$ Department of Obstetrics and Gynecology, Bayero University Kano/Aminu Kano Teaching Hospital, P.M.B. 3011. \\ ${ }^{2}$ No. 5 Nnayelugo AN Achebe Close Brains and Herners Estate Apo 3, Abuja.
}

*Corresponding Author: Dr Ayyuba RABIU. Department of Obstetrics and Gynecology, Bayero University Kano/Aminu Kano Teaching Hospital, P.M.B.3011 Email: rayyuba.gyn@buk.edu.ng

\begin{abstract}
Menstrual hygiene management services among female inmates should be in a professional manner equivalent to what is provided in the country. Female prisoners' menstrual patterns could differ from normal due to stress and uncertainty about the future. This cross sectional survey was aimed to assess the menstrual bleeding pattern of the female prisoners and their menstrual hygiene. It was conducted among three selected Prisons in Kano. Ethical approval was obtained from Ethical Committee of Kano State Ministry of Health. Information such as socio-demographic characteristics, menstrual hygiene and pattern were recorded on a questionnaire. All consenting female prisoner were recruited for the survey. Data collected were analyzed using SPSS Version 26.0.A p value of $<0.05$ was considered significant. Their mean age $( \pm \mathrm{SD})$ was $30.1 \pm 3.42$ years. The mean menstrual cycle was $28.9 \pm 4.42$ days. The average duration of menstrual flow was $3 \pm 1$. Thirty two (33.0\%) of the female prison inmates experienced pains during menstruation (dysmenorrhea) while 43 (44.3\%) had no dysmenorrhea. Majority of the inmates 83(85.6\%) took bath once during menstrual period. More than $4 / 5$ th $(81.4 \%)$ changed their absorbent twice a day during the period. Majority of the female inmates used toilet $(80 \%)$ as the method of absorbent disposal. In conclusion; the survey showed that female prisoners relatively showed regular and normal menstrual patterns. Menstrual hygiene was relatively poor.
\end{abstract}

Keywords:Female Prisoners, Hygiene, Menstrual Pattern

\section{INTRODUCTION}

$\mathrm{M}$ enstrual hygiene management refers to a situation whereby Women and adolescent girls are using a clean menstrual management material to absorb or collect menstrual blood, that can be changed in privacy as often as necessary for the duration of a menstrual period, using soap and water for washing the body as required, and having access to safe and convenient facilities to dispose of used menstrual management materials. ${ }^{1}$ Imprisonment should not deny the rights of prisoners to receive a good level of healthcare and female inmates must have the benefit of care equivalent of that available to the general public including health promotion interventions. ${ }^{2}$ In Nigeria, studies have shown that our prisons are characterized by inhumane conditions and overcrowding, leading to a deplorable health situation among inmates. ${ }^{3}$ Menstrual bleeding patterns are believed to be relevant indicators of reproductive health, and abnormal bleeding patterns may affect the quality of life for pre- and peri menopausal women. ${ }^{4}$ Menstrual irregularities affect $2-5 \%$ of childbearing women and it's 
believed to be considerably higher among women under constant stressful conditions. ${ }^{5}$ The phrase health promoting prison is used to cover the prisons in which: the risks to health are reduced to a minimum; essential prison duties such as the maintenance of security are undertaken in a caring atmosphere that recognizes the inherent dignity of every prisoner and their human rights; health services are provided to the level and in a professional manner equivalent to what is provided in the country as a whole; and a whole-prison approach to promoting health and welfare is the norm". ${ }^{6}$

A female prisoner is denied certain rights as a result of the custodian judgment passed on her by a court of law. She is restrained from movement and can, therefore, not have total assurance of enjoyment of the freedom of personal liberty under the law. ${ }^{7}$ A female inmate does not totally lose her rights as a human being and must, therefore, enjoy some basic rights despite being confined to prison. Female prisoners face health care challenges related to menstruation, pregnancy, childbirth, childcare, violence and sexual abuse in prisons all over the globe. It is pathetic to observe that female prison inmates are denied their right to health services. The African charter on human and peoples right, which Nigeria is signatory to also provides that "every individual shall have the right to enjoy the best attainable state of physical and mental health". ${ }^{8}$ But the Nigerian government is not living up to expectation as regards to provision of health care for prisoners. As a result of lack of health care system in the prison, there is a need to assess the menstrual bleeding pattern of the female prisoners and their menstrual hygiene.

\section{MATERIALS AND METHODS}

This study was a cross-sectional survey conducted among three selected Prisons (Kurmawa Prison in Kano Municipal Local Government, Goron Dutse in Dala Local Government and Wudil Prison in Wudil Local Government) in Kano, North-Western Nigeria. A list of all the prisons in Kano was made and three prisons were selected at random using a random number generator. The target population in this survey were all the reproductive female prisoners at the Three (3) Selected Prisons. Ethics approval was obtained from Ethical Committee of Kano State Ministry of Health and the approval letter was presented to the Three (3) Selected Prisons before the study was conducted. A questionnaire was structured and pretested which comprised close and open ended questions. Information such as socio-demographic characteristics, menstrual hygiene and pattern were recorded on the questionnaires. This survey followed the approach described by Patton (2002), which was a purposeful sampling technique, by using small sample population to study the phenomenon of menstrual bleeding pattern indepth and detail. All consenting female prisoner within the reproductive age who were willing to participate in the survey were recruited for the survey. Data collected were checked for completeness, code entered into Microsoft excel and analyzed using SPSS Software Version 26.0 (2016, IBM Corp., USA). The data entered were then expressed as a descriptive statistics, percentage and associations between variables were tested using the chi-square test. A $p$ value of $<0.05$ was considered significant.

\section{RESULTS}

The survey was conducted from $1{ }^{\text {st }}$ February to $31^{\text {st }}$ March 2019. During the period a total number of 97 female inmates were recruited. Their mean age $( \pm \mathrm{SD})$ was $30.1 \pm 3.42$ years. A larger proportion of the female inmates were within the age group of 18-27 years 46 (47.4\%), followed by $28-37$ years $33(34.0 \%)$. Table: 1 However, when categorization of female prisoner inmate surveyed based on Ethnic group was considered, results showed that Hausa/Fulani ethnic group were the majority $64(66.0 \%)$, followed by Igbo with $21(21.7 \%)$ and Yoruba ethnic group with 7 (7.2\%).

Christianity had the highest representative 41 (42.3), followed by Islamic religion 37 (38.1\%) and the least was Traditional religion with 19 (19.6\%) (Table: 1). A significant number of the female inmates had no formal education $40(41.2 \%)$, while those with secondary and tertiary level of education were 28 (28.9\%), 12 (12.4\%) respectively. More than half of the female prisoners were artisans $53(54.6 \%)$ while teachers were least represented $3(3.1 \%)$.

Also, the time (years) spent in prison by the female prisoners during the study showed that; those that spent $10-14$ years had the largest proportion $46(47.4 \%)$. The mean menstrual cycle was $28.9 \pm 4.42$ days, the median was 29 days with a modal of 30 days. A larger proportion of the female prisoner inmates had $30-34$ days 39 (40.2\%), 25 - 29 days 32 (33.0\%), $20-24$ days 18 $(18.6 \%)$ and 3539 days $8(8.3 \%)$ menstrual cycle (Table: 
Table 1: Socio-Demographic Characteristics of Female Prison Inmates

\begin{tabular}{|c|c|c|}
\hline Variable & Frequency & Percent \\
\hline \multicolumn{3}{|c|}{ Age group (yrs) } \\
\hline $18-27$ & 46 & 47.4 \\
\hline $28-37$ & 33 & 34.0 \\
\hline $38-47$ & 18 & 18.6 \\
\hline Total & 97 & 100.0 \\
\hline \multicolumn{3}{|l|}{ Ethnic group } \\
\hline Hausa/Fulani & 64 & 66.0 \\
\hline Igbo & 21 & 21.6 \\
\hline Yoruba & 7 & 7.2 \\
\hline Others & 5 & 5.2 \\
\hline Total & 97 & 100.0 \\
\hline \multicolumn{3}{|l|}{ Religion } \\
\hline Islam & 37 & 38.1 \\
\hline Christianity & 41 & 42.3 \\
\hline Traditional & 19 & 19.6 \\
\hline Total & 97 & 100.0 \\
\hline \multicolumn{3}{|c|}{ Educational status } \\
\hline Primary & 7 & 7.2 \\
\hline Secondary & 28 & 29.3 \\
\hline Tertiary & 12 & 12.5 \\
\hline Qur'anic & 9 & 9.3 \\
\hline None & 41 & 41.7 \\
\hline Total & 97 & 100.0 \\
\hline \multicolumn{3}{|l|}{ Occupation } \\
\hline Business & 19 & 19.6 \\
\hline Professional & 5 & 5.2 \\
\hline Artisan & 53 & 54.6 \\
\hline Farming & 17 & 17.5 \\
\hline Teaching & 3 & 3.1 \\
\hline Total & 97 & 100.0 \\
\hline \multicolumn{3}{|c|}{ Duration of stay (yrs) } \\
\hline$<5$ & 7 & 7.2 \\
\hline $5-9$ & 21 & 21.7 \\
\hline $10-14$ & 46 & 47.4 \\
\hline$\geq 15$ & 23 & 23.7 \\
\hline Total & 97 & 100.0 \\
\hline
\end{tabular}

Table 2: Patterns of Menstrual Cycle of the Inmates

\begin{tabular}{lll} 
Feature & Frequency & Percent \\
Length of menstrual cycle & & \\
$25-24$ & 18 & 18.6 \\
$30-34$ & 32 & 33.0 \\
$35-39$ & 39 & 40.2 \\
Total & 8 & 8.2 \\
Duration of flow & 97 & 100.0 \\
$1-8$ & & \\
$\geq 8$ & 83 & 85.0 \\
Total & 14 & 15.0 \\
Amount of blood flow & 97 & 100.0 \\
Normal & & \\
Scanty & 58 & 59.8 \\
Heavy & 29 & 29.9 \\
Total & 10 & 10.3 \\
Regularity of menstrual cycle & 97 & 100.0 \\
Regular all the time & & \\
Regular in majority of the time & 67 & 69.1 \\
Regular occasionally & 24 & 24.7 \\
Total & 6 & 6.2 \\
\hline
\end{tabular}

Table 3: Dysmenorrhea among Female Inmates

\begin{tabular}{lll}
\hline $\begin{array}{l}\text { Variable } \\
\text { Do you experience pain during menses? }\end{array}$ & Frequency & Percent \\
Yes, mild & 32 & 33.0 \\
Yes, moderate & 9 & 9.3 \\
Yes, severe & 13 & 13.4 \\
None & 43 & 44.3 \\
Total & 97 & 100.0 \\
How frequent you experience pain during & & \\
menses? & & \\
Always & 23 & 23.7 \\
Most of the time & 20 & 20.6 \\
Occasionally & 54 & 55.7 \\
Total & 97 & 100.0 \\
Do you experience intermenstrual bleeding? & & \\
Yes & 13 & 13.4 \\
No & 84 & 86.6 \\
Total & 97 & 100.0 \\
\hline
\end{tabular}

Table 4: Practice of Menstrual Hygieneamong Respondents

\begin{tabular}{lll}
\hline Number of bath during menses & & \\
Once & 83 & 85.6 \\
Twice & 10 & 10.3 \\
Thrice & 4 & 4.1 \\
Total & $\mathbf{9 7}$ & $\mathbf{1 0 0 . 0}$ \\
Number of absorbent changes/day & & \\
Once & 9 & 9.3 \\
Twice & 81 & 81.4 \\
Thrice & 9 & 9.3 \\
Total & $\mathbf{9 7}$ & $\mathbf{1 0 0 . 0}$ \\
\hline
\end{tabular}

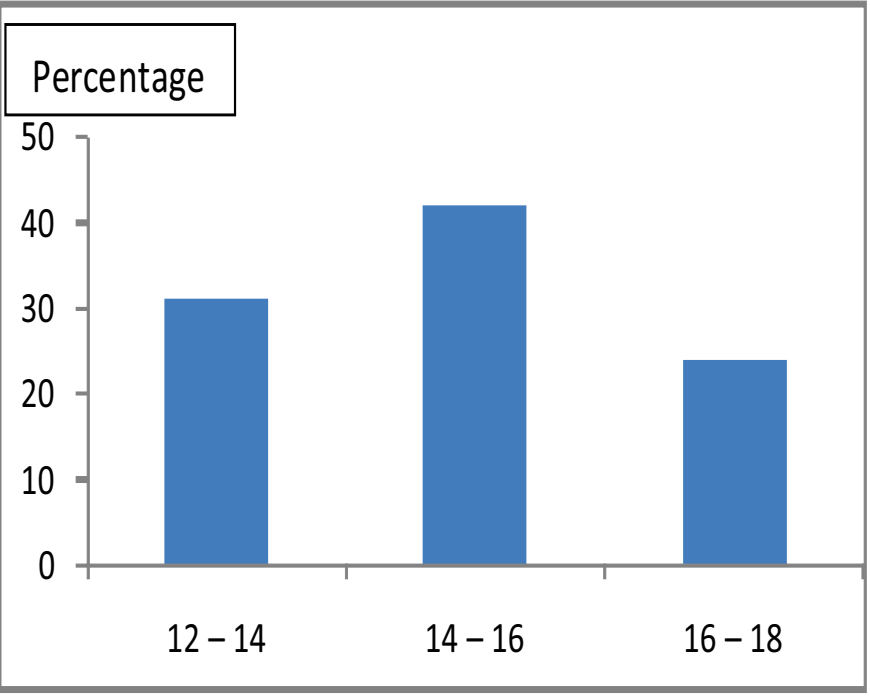

Figure 1: Age at Menarche (Years) 


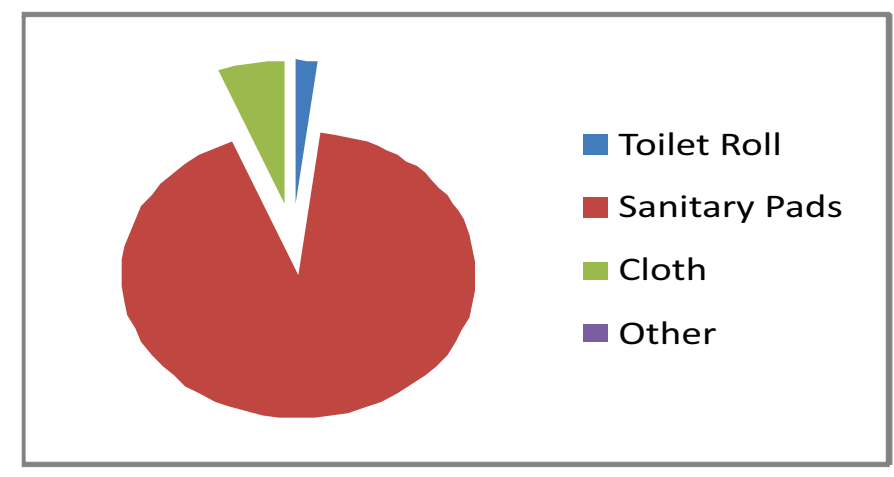

Figure 2: Types of Absorbent Used During Menses

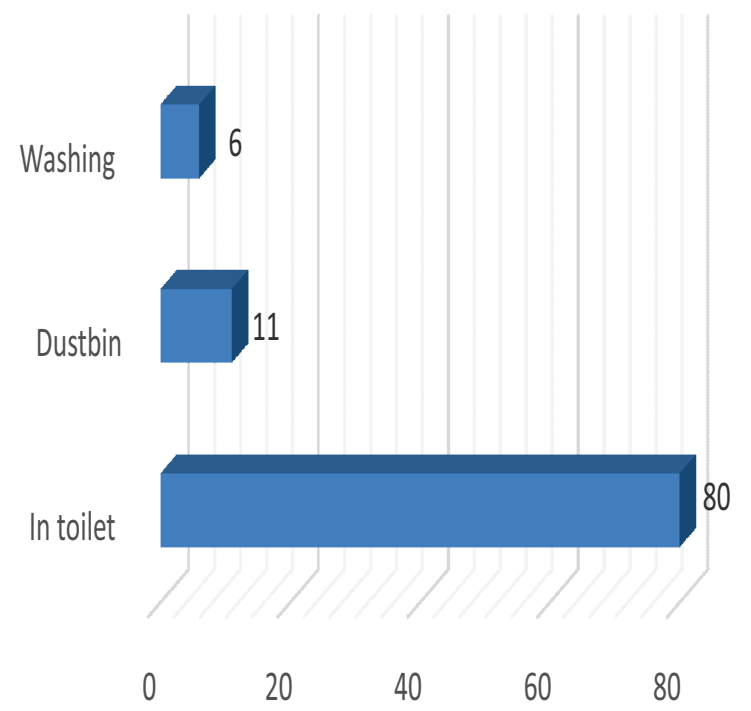

Figure 3: Methods of Absorbent Disposal

2). The average duration of menstrual flow was $3 \pm 1$ days. The amount of blood flow was normal in $58(59.8 \%)$, scanty/light in $29(29.9 \%)$, and heavy in $10(10.3 \%)$ of the female prisoner inmates (Table 2).

The menstrual cycle was regular all the time 67 (69.1\%), regular in majority of the time $24(24.7 \%)$ and regular occasionally $6(6.2 \%)$ among the female prisoner inmates (Table 3).Also, age at menarche among female inmates was higher between $15-18$ years with 42 (43.3\%), followed by 12 -14 years with 31 (32\%) and the least between $18-20$ years with 24 (24.7\%). Figure 1

Thirty two $(33.0 \%)$ of the female prisoner inmates experienced pains (dysmenorrhea) during menstruation while 43 (44.3\%) had no dysmenorrhea. Among those that had dysmenorrhea, $54(55.7 \%)$ experienced it occasionally, $23(23.7 \%)$ always and $20(20.6 \%)$ most of the time. Only 13
(13.4\%) experienced intermenstrual bleeding (metrorrhagia). Table 4 showed the practice of menstrual hygiene among the inmates. Majority of the inmates $83(85.6 \%)$ took bath once during menstrual period. More than $4 / 5^{\text {th }}(81.4 \%)$ changed their absorbent twice a day during the period.

Figure 1 showed the age at menarche. The mean age at menarche was $14.9 \pm 1.51$ years. The median age was 15 years. A larger proportion of the inmates attained menarche at 14-16 years. Figure 2 depicted the types of absorbent used during menses. Sanitary pad (92\%) was the most used by the inmates.

Majority of the female inmates used toilet $(80 \%)$ as the method of absorbent disposal, followed by dustbin (11\%). Figure 3

\section{DISCUSSION}

In this survey, the mean menstrual cycle was $28.9 \pm 4.42$ days with a median of 29 days. This was similar to the mean menstrual cycle of 29.7days among Igbo women of South Eastern Nigeria. ${ }^{9}$ It was higher than the figure of $27.5 \pm 8.76$ days reported by Rabiu et al. ${ }^{10}$ in Kano, North Western Nigeria. However, the finding is within the normal range of 21 days to 35 days. ${ }^{11}$ Our findings showed that female prison inmates had normal menstrual cycle despite high level of stress and uncertainty about their future life. The duration of flow was 1 to 8 days in about $85 \%$ of the inmates which is within the normal range reported by Umeora and Egwuatu in Enugu. Only $10.3 \%$ of the inmates had heavy menstrual flow. This was slightly higher than $7.1 \%$ reported among female medical students in University of Maiduguri, Nigeria. ${ }^{12}$ Difference in age group between the female inmates and the medical students in Maiduguri could be responsible for the varying figures. Only $6.2 \%$ of the inmates presented with occasionally regular menstrual cycles. All other inmates had regular menstrual cycle $(93.8 \%)$. This showed that despite sub optimal standard level of hygiene, high level of anxiety and stress coupled with uncertainty of future normal life among the female inmates, irregular menstrual cycle was highly uncommon. Our study revealed that menstrual cycle was regular all the time 67 (69.1\%), regular in majority of the time $24(24.7 \%)$, regular occasionally $6(6.2 \%)$, and irregular (unpredictable) $0(0.0 \%)$ among the female prisoner inmates (Table: 4.2). Rabiu et al showed that the menstrual cycle was regular all the time 96 (44.1\%), regular in majority of the time 87 (39.7\%), regular occasionally $11(5.0 \%)$, and irregular 24 
$(11.0 \%)$ among the adolescent girls. Our study and their findings suggested that most of the female have a regular menstrual cycle.

In this survey, $32(33.0 \%)$ of the female prison inmates experienced pains during menstruation(dysmenorrhea). This was lower than the figure of 93 (42.5\%) reported by Rabiu et $a l^{10}$ among adolescent school girls in kano. However, an alarming figure of $299(83.1 \%)$ of dysmenorrhea was reported by Bello and colleagues ${ }^{13}$ among female students at a Teaching Hospital in South-Western Nigeria. Based on these findings, the rate of dysmenorrhea was also within normal findings. Only $13(13.4 \%)$ experienced intermenstrual bleeding (metrorrhagia) in this study. This was similar to the finding of Rabiuet al. ${ }^{10}$ who reported $12.5 \%$ among adolescent school girls in Kano.

Our study revealed $43.3 \%$ of female prisoners attained menarche at $15-18$ years. The mean age at menarche was $14.9 \pm 1.51$ years. The median age was 15 years. This was slightly lower than the mean age at menarche of 15.26 years reported among school girls in Sokoto, North Western Nigeria $^{14}$ and higher than the mean age at menarche of $12.83 \pm 1.312$ reported among adolescent school girls in kano, North Western Nigeria ${ }^{15}$ but within the age range of 1014 years reported by Fagbamigbe and colleagues ${ }^{16}$ in Ibadan, South Western Nigeria. Similarly, a study by Balamurugan et $a l .{ }^{17}$ foundmajority of women attained menarche at the age of 13-15 years. This showed that attainment of menarcheal age by female prisoners falls within normal age group in our community and are unlikely to influence abnormal menstrual patterns among prisoners.

Considering menstrual hygiene among female prisoners, we found $85.6 \%$ of the inmates only took bath once during the duration of menstruation. This was inadequate and it demonstrated poor menstrual hygiene and quality of life. Majority of the inmates $89(91.8 \%)$ used sanitary pads, followed by cloths $6(6.2 \%)$ and toilet roll $2(2.1 \%)$ during menstruation. Santral 8 in a slum of Kolkata, West Bengal, India, revealed that though $97 \%$ of women opined that sanitary pad is the ideal absorbent to be used during menstruation, only $65 \%$ women used sanitary pad and $30 \%$ used cloth pieces. Majority of the inmates ( $80 \%)$ used toilet for disposal of menstrual absorbent. Only a few $(6 \%)$ recycled their absorbents by washing.

\section{CONCLUSION}

The survey showed that despite stressful condition and uncertainty faced by female prisoners, they relatively showed regular and normal menstrual pattern obtainable among women of child bearing age groups. Menstrual hygiene was relatively poor; majority of female inmates took bath once only during the entire period of menses and most of the used absorbents were disposed in the toilets.

\section{Recommendations}

Non-governmental organization should come forward to educate female prisoners on menstruation, menstrual hygiene management, hand washing and diseases related reproductive tracts due to poor hygiene. Female prisoners should be aware of consequences of disposing used menstrual product in open or flushing them in toilet. Dustbin with proper lids should be placed in the toilet. If possible, incinerators should be installed in the prisons.

\section{Conflict of interest}

None

\section{REFERENCE}

1. Johnson L, Calderón T, Hilari C, Long J, Vivas C. "Menstrual Hygiene Management Impacts Girls' School Experience in the Bolivian Amazon", United Nations Children's Fund, La Paz Bolivia, May 2016.

2. Health promoting prisons: an overview and critique of the concept. Available from : http://eprints.leedsbeckett.ac.uk/98/1/Article\%20for\%20 consideration\%20in\%20PSJ_Health\%20promoting\%20 prisons.pdf. Accessed on 13/11/2019.

3. Solomon OJ, Nwankwoala R, Ushi V. The plight of female prisoners in Nigeria and the dilemma of health rights violations. Asian J Social Scie Humanities. 2014; 3(4) :152-61.

4. Rebar R. Evaluation of Amenorrhea, Anovulation, and Abnormal Bleeding [Internet]. In: Feingold KR, Anawalt B, Boyce A, Chrousos G, Dungan K, Grossman A, et al., editors. Endotext. South Dartmouth (MA): MD Text.com, Inc.; 2000 [cited 2019 Nov 10]. Available from: http://www.ncbi.nlm.nih.gov/books/NBK279144/

5. Nagma S, Kapoor G, Bharti R, Batra A, Batra A, Aggarwal A, et al. To Evaluate the Effect of Perceived Stress on 
Menstrual Function. J Clin Diagn Res 2015;9(3):QC01-3.

6. Møller L, Stöver H, Jürgens R, Gatherer A, Nikogosian H. Health in prisons $\mathrm{A}$ WHO guide to the essentials in prison he a $1 \mathrm{th}$. 2007 ; Ava i lab 1 e from: http://www.euro.who.int/_data/assets/pdf_file/0009/99 018/E90174.pdf. Accessed on 13/11/2019

7. Araromi MA. Prisoners' rights under the Nigerian Law: Legal Pathways to Progressive Realization and Protection. Afe Babalola University: J Of Sust Dev Law \& Policy 2015;6(1):170-98.

8. African Charter on Human and Peoples' Rights. [cited 2019 Nov 10]; Available from: http://www.nigerialaw.org/African\%20Charter\%20on\%20Human\%20and \%20Peoples\%20Rights.htm

9. Umeora O, Egwuatu V. Age at Menarche and the Menstrual Pattern of Igbo Women of Southeast Nigeria. Afr J Reprod Health. 2008;12(1):90-5.

10.Rabiu A, Abubakar IS, Garba I. Dysmenorrhea and menstrual patterns among adolescent school girls in Kano. N Niger J Clin Res [serial online] 2019 [cited 2019 Nov 13];8:30-4. Available from: http://www.mdcanuath.org/text.asp?2019/8/13/30/252585

11. Normal Menstruation. Cleveland Clinic [cited 2019 Nov 10 ]; A v a i 1 a b 1 e

f $r$ o $\mathrm{m}$ : https://my.clevelandclinic.org/health/articles/10132normal-menstruation

12. Amaza DS, Sambo N, Zirahei JV, Dalori MB, Japhet H, Toyin Menstrual pattern among female medical students in University of Maiduguri, Nigeria. Br J Med Med Res 2012;2:327-37.

13. Bello FA, Akinyotu OO, Odubamowo KH. Dysmenorrhea among female students at a Teaching Hospital in SouthWestern Nigeria. Trop J Obstet Gynaecol [serial online] 2017 [cited 2019 Nov 13];34:129-33. Available from: http://www.tjogonline.com/text.asp?2017/34/2/129/2134 $\underline{36}$

14. Tunau K A, Adamu A N, Hassan M A, Ahmed Y, Ekele B A. Age at menarche among school girls in Sokoto, Northern Nigeria. Ann Afr Med [serial online] 2012 [cited 2019 Nov 13];11:103-7. Available from: http://www.annalsafrmed.org/text.asp?2012/11/2/103/93 $\underline{533}$

15. Garba I, Rabiu A, Abubakar IS. Age at menarche and its association with overweight/obesity among adolescents in Kano. J Med Trop [serial online] 2017 [cited 2019 Nov 13 ] ; $19: 90-2$. Ava i 1 a b 1 e from: http://www.jmedtropics.org/text.asp?2017/19/2/90/2184 $\underline{05}$

16. Fagbamigbe AF, Obiyan MO, Fawole OI. Parametric survival analysis of menarche onset timing among Nigerian girls. Heliyon. 2018;4(12):e01105. Published 2018 Dec 28. doi:10.1016/j.heliyon.2018.e01105

17. Balamurugan SS, Shilpa SS, Shaji S. A community based study on menstrual hygiene among reproductive age group women in a rural area, Tamil Nadu. J Basic Clin Reprod Sci 2014;3:83-7.

18. Santra S. Assessment of knowledge regarding menstruation and practices related to maintenance of menstrual hygiene among the women of reproductive age group in a slum of Kolkata, West Bengal, India. Int J Community Med Public Health 2017;4:708-12. 